\title{
Benin experience of Decentralized Steering Committee in the institutional framework of Results-Based Financing: elements for players' empowerment at local level
}

David Houeto ${ }^{1 *}$, Graziella Ghesquiere ${ }^{2}$, Maurice Agonnoude ${ }^{1}$, Amavi Hounouvi $^{2}$, Karel Gyselinck ${ }^{3}$ and Mohamed Lamine Drame ${ }^{2}$

*Correspondence: dhoueto@gmail.com

${ }^{1}$ School of public health, University of Parakou, Benin.

${ }^{2}$ Belgian Development Agency (BTC), Cotonou, Benin.

${ }^{3}$ Belgian Development Agency (BTC), Brussels, Belgium.

\begin{abstract}
Introduction: In 2012, Belgian Development Agency (BTC), at the request of Benin Authorities, introduced a Results-Based Financing (RBF) mechanism in two Regions to improve health system performance. The purpose is to grant subsidies to providers and managers of care and services on a performance basis. Two regional steering committees (SC) chaired by mayors have been set up with health care and civil society representatives. Mayors were given the position of buyer of performances on behalf of beneficiaries. The aim is to study the institutional arrangements for the management of BTC's RBF at the decentralized level in relation to its effectiveness in the context of supply/demand dialogue, community empowerment, better coordination between local Governments and Health, and improving care quality.

Methods: This is a cross-sectional study with retrospective and prospective data collection. The study population is made up of players involved in the RBF. Data collection was carried out through the documentary review of the RBF experiences in Benin. The analysis was conducted by identifying the strengths, weaknesses, opportunities and threats of the SC at the decentralized level.

Results: Regular meetings of the SC focuses henceforth on the resolution of concrete problems through a constructive dialogue between supply and demand; Community participation has shifted from information to co-decision making; Enhanced accountability: providers and managers report on their performance to the reporting line, mayors and the Civil Society; The presence of the Civil Society and the mayors ensures compliance with the principle of performance-based payment and contributes to the fight against fraud and impunity; Complaints management data and community verification feed into the supervision of the Health zone management team; Progressive financing of the SC functioning by the municipalities and; Improving satisfaction of health services users.

Conclusions: SC at the decentralized level promotes stakeholder engagement for people's access to health care; It shows the need for a permanent framework of exchanges among players at the decentralized level to improve the provision of care; Involvement of mayors in a process of improving care quality and at a decision-making level is a guarantee of responsibility and community involvement.
\end{abstract}

Keywords: RBF, decentralized steering committee, community empowerment, sustainability

\section{Introduction}

According to Canavan et al. [1], results-based financing (RBF) is a method of financing focused on the assumption that linking motivations to the performance would help to improve accessibility, quality and equity in the provision of health services.
Blanchett quoted by Canavan et al., [1] argues that its impact would vary according to the providers' demographic and organizational characteristics including the volume of activities, existence or non-existence of a competitive local environment, acceptance of wage subsidies and players trust to the merits 
of this funding mechanism.

The institutional framework of the RBF is usually developed around five main functions commonly recognized in the mechanism implementation. The first function is the regulation which is to oversee the entire implementation process and ensure its compliance with standards. It is provided by the Ministry of Health $(\mathrm{MoH})$, its central and technical departments as well as decentralized structures. The second function is the quarterly assessment of the quality of health facilities. It is provided by the decentralized structures of the $\mathrm{MoH}$. The third function is the funding provided by the Donors. The fourth function is related to the purchase of performance which comprises validation and payment of invoices provided by the Project Coordination Unit (PCU) standing as the executive structure. Finally, the fifth, the verification and certification of invoices from different structures of suppliers of care and services. It consists of the verification of quantities with the RBF independent external control agency and community verification provided by Community-Based Organizations (CBO).

\section{The Steering Committee (SC) and its objectives}

To improve project monitoring and validate the strategic choices in order to help the project leader avoid making decisions outside his prerogative, there is a need of setting up a cross-functional team: the SC. The SC usually involves a member of each line of the project work including the product user.

For complex projects/programs such as those of health, we can distinguish: (i) an operational SC (regular monitoring of the project progress, decision-making in a delegation process,...); (ii) a SC more strategically orientated which often involves the company or organization leaders, able to make decisions that go beyond the responsibilities of the operational SC.

As part of the RBF, the following have been set up: (i) at the central level, policies development and global resources mobilization; (ii) at the intermediate level, the interpretation of the standards and policies and coaching of the peripheral level of the health system for their implementation; (iii) at the operational level, the effective implementation of these policies with adaptation to realities on the ground. Lessons learned get back to the central level through the intermediate level in order to feed thoughts on various reforms. This is to support the different levels of the health system to become a learning organization. RBF implementation should take into account these data in order to be able to contribute to strengthening the health system.

This study proposes to answer the question: what is the contribution of a decentralized SC in improving dialogue between care providers and communities, community empowerment and care quality?

\section{Study area and methods}

Study area

Benin, like all developing countries, is characterized by high mortality rates at all ages. According to estimations, infant mortality rate dropped from 89\%o in 2001 (DHS-II) to 67\%o in 2006 (DHS III) and maternal mortality rate was estimated at 397 per 100,000 live births (DHS-III) [2]. Life expectancy at birth was 56.5 years in 2012.

\section{Methods}

It is a cross-sectional study with retrospective and prospective data collection. The study population consists of stakeholders of the RBF decentralized SC in Benin. Data collection is performed through two techniques:

1. Document review on the RBF experience in Benin fed when necessary with RBF experiences in other countries in similar context;

2. In-depth interview with field stakeholders involved in the implementation of the experience.

Selection of interviewees was based on expert choice from the central level of the health system to the local level including local government authorities. Data were collected using an in-depth semi-structured interview guide. Topics discussed include the effectiveness of the model in the health care providers and caregivers' dialogue, taking into account the communities' point of view through their representatives or local leaders, empowering these communities; improving care quality; and the sustainability of both RBF and its achievements in terms of health outcomes for the population. These topics have been chosen based on the empowerment process [4] that needs community participation and control of the action under implementation, a process that leads to sustainability. The RBF effects in terms of health outcomes have been also taken into account. Because the timeframe of the RBF implementation is too short, health outcomes have been assessed through users' satisfaction only using the percentage of people in the community that have received care with satisfaction. We used results of the quarterly assessments made by the RBF team.

Data processing was manual by thematic grouping taking into account the above topics. Data analysis was made with emphasis on the strengths, weaknesses, opportunities and threats of the decentralized SC model.

\section{Results}

In the case of Benin, the RBF beneficiary is the health facilities, and results are quantity and quality of the care provided. It aims to improve the health system performance in the provision of quality care to populations, especially the poorest and vulnerable.

There were ten stakeholders interviewed from the central to the local level including a Mayor.

\section{Description of the BTC SC experience and its institu- tional framework}

The BTC experience of RBF started in 2012 with the main aims of (i) strengthening national healthcare structures in their mission, mandate and activities; (ii) empowering com- 
munities through the right to health approach; (iii) creating an accountability process between all the local health system (LHS) players and; (iv) developing LHS through the togetherness of its different players and improving the care quality.

In regard to the RBF, the BTC experience has some specificities such as: (i) involvement of the regional health directors (RHD) in the peers evaluation (which comes as part of the $2^{\text {nd }}$ function), (ii) Mayors as the buyers of the performance (as part of the $4^{\text {th }}$ function, and (iii) the verification at community level by the PUSS (Figure 1).

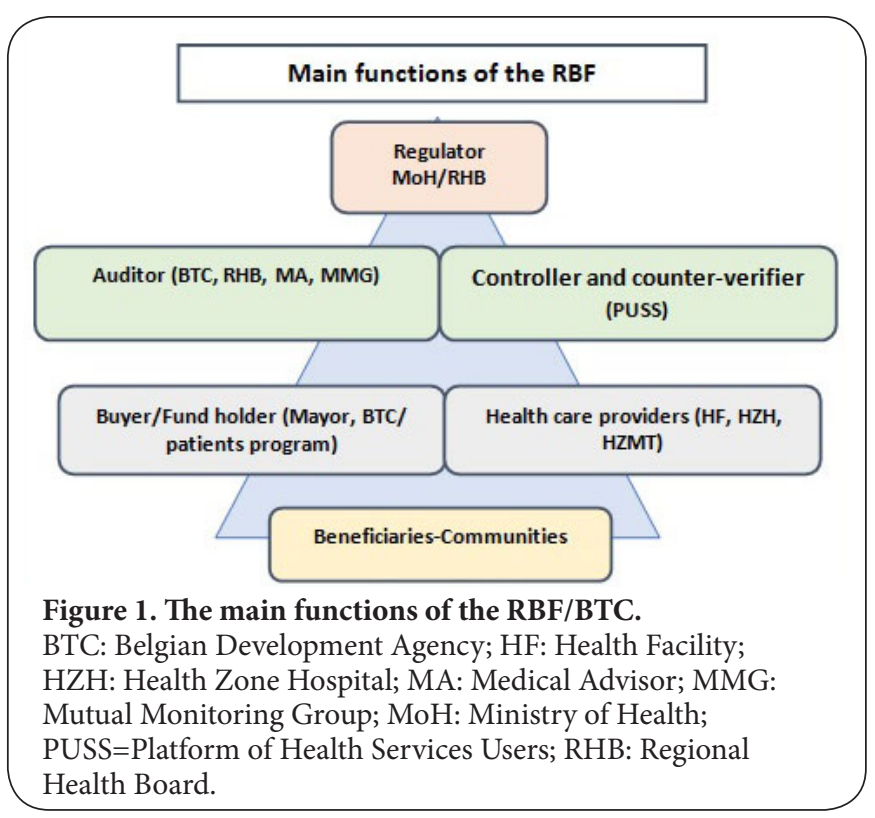

The health zone management team (HZMT), although not quite in the spirit of the "district health" as declared by the Dakar conference [3], has other missions through the six pillars of the district development namely: governance, human resources, healthcare delivery, funding, drugs and vaccines and logistics as well as the health information system. A performance contract focusing on these six pillars is signed between the SC and the HZMT.

Tables 1 and 2 display the characteristics of the BTC/RBF experience compared to the centralized one.

The Figure 1 summarizes the distribution of the different functions of RBF in the context of the BTC experience.

In summary, with regard to RBF implementation, BTC experience is moving towards the scheme recommended by Toonen and Coolen [4] (Figure 2) as part of West African decentralization and experience and focuses on decentralized piloting with community participation in order to take into account the local context and realities.

Effectiveness of the model in the supply-demand of care dialogue

The PUSS, as representative of the community is the SC mem-

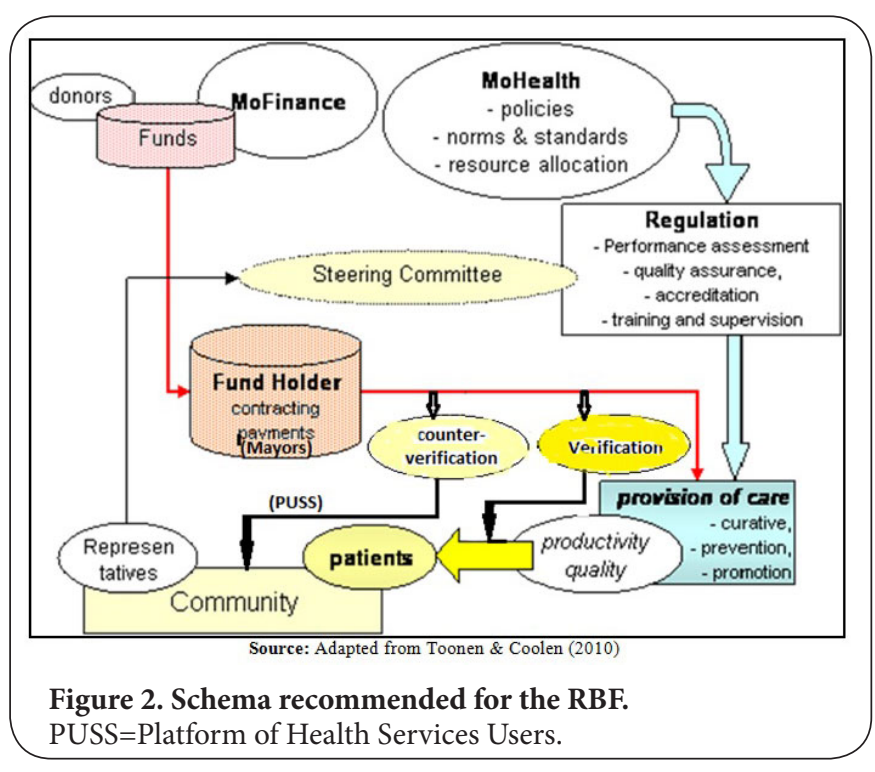

ber. It conducts, among others, data collection on complaints and in the verification at community level and ensures their return to HFs. Counter-verifications are organized and integrated supervisions (pools of expertise) are called upon to speak based on significant and concrete elements. It thereby establishes a permanent dialogue between the supply and demand of care.

\section{Contribution to strengthening decentralization and communities' empowerment}

According to stakeholders, practices are based on the local level HFs performance analysis. The result is a process of compensation of HFs and HZMT by the SC members including demand represented by PUSS and mayors. Moreover, the SC members are involved in a process of capacity-building while implementing the SC activities in order to play their role to the best of their ability.

\section{Improvement of care quality}

RBF stakeholders reported that community participation to the SC through PUSS and mayors weighs in the process of HFs services purchasing. Moreover, counter-verification through the effectiveness of care is assigned to the PUSS and is part of care quality assessment. Since the beginning of RBF implementation in the BTC concentration areas, the trend is the users' satisfaction improvement over evaluations, with a stagnation over $80 \%$ since the $2^{\text {nd }}$ quarter of 2015 . Charts 1 and 2 below present the trend of the scores of peoples' satisfaction.

\section{Discussion}

We discuss these results through three main elements related to the empowerment process as mentioned earlier $[3,4]$ and which are: effectiveness of the decentralized SC model in the supply-demand of care dialogue; contribution to strengthening 
Houeto et al. Journal of Public Health Aspects 2017,

http://www.hoajonline.com/journals/pdf/2055-7205-4-1.pdf

Table 1. Framework of compared centralized and decentralized (BTC) SC implementation models.

\begin{tabular}{|c|c|c|c|}
\hline Bodies & & Centralized & Decentralized (BTC) \\
\hline \multirow[t]{3}{*}{$\mathrm{SC}$} & Level & Central & Regional \\
\hline & Composition & Members of the HSS platform & $\begin{array}{l}\text { - Deliberative voice: mayors, ITA/BTC, RHB, medical advisor, PUSS } \\
\text { - Consultative voice: Health Committee (HC), RTA/BTC } \\
\text { - Resource-persons according to the needs }\end{array}$ \\
\hline & Activities & $\begin{array}{l}\text { - Strategic decisions; } \\
\text { - Monitoring; } \\
\text { - Implementation coordination } \\
\text { at all levels; } \\
\text { - Provide strategic guidance for } \\
\text { implementation; } \\
\text { - Validate the implementation } \\
\text { redesigning; } \\
\text { - Mobilize resources from Gov- } \\
\text { ernment and Donors for RBF. }\end{array}$ & $\begin{array}{l}\text { - Discuss and validate the RBF implementation tools; } \\
\text { - Validate eligibility of health facilities; } \\
\text { - Validate results of assessments; } \\
\text { - Validate the list of benefits to be financed taking into account public } \\
\text { health priorities defined by the MoH; } \\
\text { - Validate the maximum of amount of benefits purchasing with regard to } \\
\text { the agreements with donors; } \\
\text { - Inform the RDH of the administrative and/or technical faults perpe- } \\
\text { trated by health care providers; } \\
\text { - Validate the list of financial and other punishments based on informa- } \\
\text { tion transmitted by the pool of the RBF technicians; } \\
\text { - Arbitrate in the event of conflict between stakeholders; } \\
\text { - Develop strategies that encourage other donors to fund RBF; } \\
\text { - Report to the regional committee of projects/programs monitoring and } \\
\text { evaluation. }\end{array}$ \\
\hline \multirow[t]{3}{*}{ Regulator } & Level & Central/Regional & Regional \\
\hline & Composition & $\begin{array}{l}\text { Central departments of the } \mathrm{MoH} \text {, } \\
\text { MI and others e.g. regional } \\
\text { health boards }\end{array}$ & Regional health boards \\
\hline & Activities & $\begin{array}{l}\text { - Monitors implementation of } \\
\text { the system on a daily basis; } \\
\text { - Participates in HF evaluations } \\
\text { at peripheral level; } \\
\text { - Assures compliance with the } \\
\text { standards; } \\
\text { - Supervises the process; } \\
\text { - Participates in the quality } \\
\text { verification. }\end{array}$ & $\begin{array}{l}\text { - Take into account health policy norms and standards enacted by the } \\
\text { central level; } \\
\text { - Proceed with the allocation of resources; } \\
\text { - Assess the performance; } \\
\text { - Guarantee quality insurance; } \\
\text { - Proceed to accreditation (integration of private HFs in the RBF by } \\
\text { checking their conformation with required standards); } \\
\text { - Proceed with the training and supervision; } \\
\text { - Participate in the verification of the quality and quantity. }\end{array}$ \\
\hline \multirow[t]{3}{*}{ Providers } & Level & Peripheral & Peripheral \\
\hline & Composition & HFs, peripheral hospitals & $\mathrm{HFs}, \mathrm{HZH}$ \\
\hline & Activities & - Provide care to the population. & $\begin{array}{l}\text { - Preventive, curative, promotional, and re-adaptive healthcare delivery; } \\
\text { - Development of business plan; } \\
\text { - Organize the mutual monitoring group with the involvement of the co- } \\
\text { management bodies. }\end{array}$ \\
\hline \multirow[t]{3}{*}{ Buyer } & Level & Central & Local \\
\hline & Composition & PCU & $\begin{array}{l}\text { Mayors (from a common basket of funds from various sources (currently } \\
\text { the BTC) }\end{array}$ \\
\hline & Activities & $\begin{array}{l}\text { - Checks operations (quantity, } \\
\text { quality, accuracy) } \\
\text { - After checking, subsidizes the } \\
\text { claimant }\end{array}$ & $\begin{array}{l}\text { - Contract; } \\
\text { - Payment. }\end{array}$ \\
\hline \multirow[t]{3}{*}{ Auditor } & Level & Central & Peripheral \\
\hline & Composition & $\begin{array}{l}\text { Technical assistant (TA) and CBO } \\
\text { Consortium }\end{array}$ & $\begin{array}{l}\text { PUSS, Regional technical assistant (RTA) - peers (from HFs, hospitals, } \\
\text { RHB and the HZMT (from another region) }\end{array}$ \\
\hline & Activities & $\begin{array}{l}\text { - Technical audit; } \\
\text { Verification at community } \\
\text { level. }\end{array}$ & $\begin{array}{l}\text { - Technical audit; } \\
\text { - Verification at community level (counter-verification and satisfaction } \\
\text { survey); } \\
\text { - Complaints management. }\end{array}$ \\
\hline \multirow[t]{3}{*}{ Donors } & Level & Central & Central \\
\hline & Composition & Donors/HSS/MoH & BTC \\
\hline & Activities & - Funding and supervision. & $\begin{array}{l}\text { - Funding; } \\
\text { - Technical support. }\end{array}$ \\
\hline
\end{tabular}


Table 2. Cycle of the RBF with centralized and decentralized SC.

\begin{tabular}{|c|c|c|}
\hline Activities & Centralized SC & BTC decentralized SC \\
\hline Annual & $\begin{array}{l}\text { - RBF contract negotiation; } \\
\text { - Communication on RBF } \\
\text { contracts; } \\
\text { - Accounting audit of RBF } \\
\text { expenditures. }\end{array}$ & $\begin{array}{l}\text { Interdepartmental workshop: } \\
\text { - Assesses RBF implementation in its main functions; } \\
\text { - Shares experiences among different players; } \\
\text { - Revises the RBF framework of implementation; } \\
\text { - Harmonizes practices in the two sub-territories; } \\
\text { - Identifies the alternatives of accompaniment of HFs, HZH and HZMTs in } \\
\text { connection with the end of the RBF funded by the BTC; } \\
\text { - Revises the assessment grids. }\end{array}$ \\
\hline Semi-annual & Quality cross-checking & \\
\hline Quarterly & $\begin{array}{l}\text { - Measures and checking of } \\
\text { RBF results; } \\
\text { - Determination of the amount } \\
\text { of the credit RBF; } \\
\text { - Payment of the credit; } \\
\text { - Allocation of the credit; } \\
\text { - Spending on credit. }\end{array}$ & $\begin{array}{l}\text { - Checks that HFs take their commitments in implementing their plan of } \\
\text { results, transparency in management, respect for the rules and procedures of } \\
\text { the agreement; } \\
\text { - Checks that various SC members are fulfilling their commitments in terms of } \\
\text { support to the RBF implementation; } \\
\text { - Validates the weighting of the results obtained after the audit reports; } \\
\text { - Validates the amount to be transferred by the payer to the contracting } \\
\text { structures HZMT, HZH, HF, etc.); } \\
\text { - Monitors the SC recommendations; } \\
\text { - Presents the results of community verification and complaints management } \\
\text { to the executive committees expanded to co-management bodies. }\end{array}$ \\
\hline
\end{tabular}
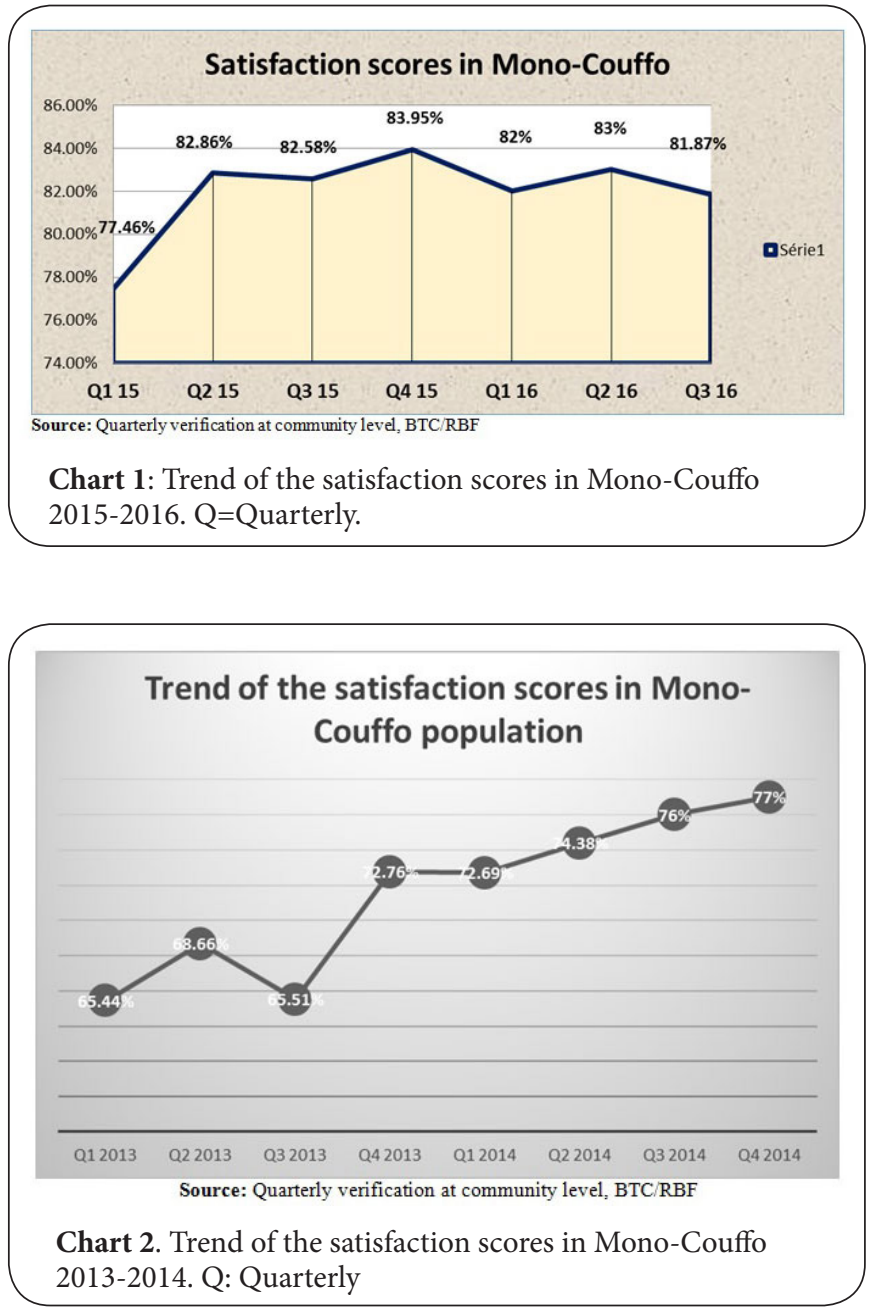

decentralization and communities' empowerment and the care quality improvement.

\section{Effectiveness of the model in the supply-demand of care dialogue}

To make care available to patients, it is important that people are an integral part of the implementation process for healthcare provision according to primary health care (PHC) [7]. $\mathrm{PHC}$ are so fundamental that any program that sidelines the basic principles of strengthening the LHS, e.g., the demand participation, intersectorality, improving living conditions, etc. is condemned to failure [5].

Experience supported by BTC shows the process of the complaints management implemented by the PUSS, the mayors and the provision of care is a contributor to the supply-demand dialogue. In the case of Rwanda reported by Morgan [8], SC is placed at the District level with involvement of communities' representatives and thus allowed the mixing between the supply and demand of care. The BTC experience based on Figure 2 [6], in the long term is a contributor to RBF rooting. According to McFarlane and Fehir [9], it will take two to five years for the community to get control of the whole process. As far as we are concerned, we think that this term will also depend on the initial level of powerlessness of each community or the quality of its assets, its willingness to change, its health status and quality of life, and also will depend on the strength of the role the professionals played at the beginning of the intervention process by really giving power to the community [3].

\section{Contribution to strengthening decentralization and communities' empowerment}

Decentralization of the health system and its effect on com- 
munity empowerment are concepts well acquired and supported for example by the Harare and Dakar declarations $[5,10]$. The effectiveness of the health system in terms of action on the social determinants of health depends deeply on it [5]. A strong and sustainable RBF needs thereby to be based on these concepts. Considering the BTC experience, positioning the SC at a local level could facilitate the learning of the exercise of responsibility by local authorities and eventually contributes to their empowerment. Learning how to solve issues raised up by the RBF implementation, knowing the mechanisms of the RBF funding and learning how to get the Donors support for that funding are all elements contributing to local stakeholders empowerment and which deserve to be taken into account in this initial phase of the RBF implementation [11]. In this sense, the SC structuring in the BTC experience could at long term be an asset in contributing to the health system decentralization and local authorities' empowerment. Nationally, as it is the case in Rwanda, the SC at decentralized level in the structuring of the RBF institutional framework depends largely on the structuring of the health system in place. It is certainly easier to use such a design as long as the health system is engaged in the process of district health.

\section{Improvement of care quality}

Although it would take time before to be able to assess the effect of RBF on the improvement of care quality, we could still note elements contributing to this end. For instance, the process of complaints management involving the return of data to the weakest HFs, the counter-verification and pools of expertise who meet to resolve the various problems identified are meaningful and concrete elements involved in improving care quality. Furthermore, community participation both by the PUSS and by the individuals in the community to verification and counter-verification activities is likely to contribute to care quality improvement. Counter-verification weighs in retribution to HFs, and so is a factor that contributes to questioning HFs regarding the quality of their services. Also, strengthening decentralization and empowerment [5] in the implementation of the RBF is an important factor in improving care quality by strengthening demand as a valid interlocutor towards the supply of care. Indeed, community participation in its type of community development allows to give to local stakeholders the opportunity to take an active role in an intervention (here RBF), to benefit from capacity-building activities and thereby aim community building. With the acquired skills, the community is able for example to require proper care from health care providers. The decentralization of $\mathrm{SC}$ with a role for local stakeholders is part of improving care quality [3]. The Rwandan experience [8] of decentralized SC has been successful in the implementation of the RBF with significant results in terms of improved maternal and child health.

\section{Conclusion}

In Benin, the RBF process that is implemented by BTC decentral- ized the SC with positive consequences on the quality of the supply-demand dialogue, the strengthening of decentralization and communities' empowerment and the care quality improving. But in a process of scaling it up, it should be better to consider the reform of the health system structure in terms of its decentralization.

With regard to prospects and recommendations for community empowerment, strengthening decentralization leads to greater empowerment with consequences for communities, among others, a much greater demand for care quality in the case of RBF and the sustainability of the action [4]. Local stakeholders being involved in the process and, at the same time, in a learning situation through capacity-building activities, it is highly likely that they pursue the approach and therefore its sustainability [10].

This tendency to conform to the pattern recommended for RBF [6] could, over time, lead to a community empowerment in the health system. That is the purpose of RBF scaling up in Benin to follow the scheme recommended in the West African context in general and Benin in particular (Figure 2).

In view of the foregoing, it is important to take the health system as a whole with as corollary the empowering participation of communities through effective decentralization process. Considering the RBF implementation process with a decentralized SC should make a great contribution in improving dialogue between care providers and communities, community empowerment and care quality. The RBF/BTC in Benin seems to favor such a process that should be put on a scale with a view to sustainable results in this case.

\section{List of abbreviations}

BTC: Belgian Development Agency CBO: Community-Based Organizations

COP: Community of Practice Health Service Delivery

RTA: Regional Technical Adviser

DHS: Demographic and Health Survey

HC: Health Committee

HF: Health Facility

HSS: Health Service Strengthening

HZH: Health Zone Hospital

HZMT: Health Zone Management Team

ITA: International Technical Assistant

LHS: Local Health System

MA: Medical Advisor

MI: Ministerial Inspection

MMG: Mutual Monitoring Group

$\mathrm{MoH}$ : Ministry of Health

PCU: Project Coordination Unit

PHC: Primary Health Care

PUSS: Platform of the Health Services Users

RBF: Results-Based Financing;

RHB: Regional Health Board

RHD: Regional Health Directors

SC: Steering Committee

TA: Technical Assistant

\section{Competing interests}

The authors declare that they have no competing interests. 
Houeto et al. Journal of Public Health Aspects 2017,

\section{Authors' contributions}

\begin{tabular}{|l|c|c|c|c|c|c|}
\hline Authors' contributions & DH & GG & MA & AH & KG & MLD \\
\hline Research concept and design & $\checkmark$ & $\checkmark$ & $\checkmark$ & $\checkmark$ & $\checkmark$ & $\checkmark$ \\
\hline Collection and/or assembly of data & $\checkmark$ & $\checkmark$ & $\checkmark$ & $\checkmark$ & $\checkmark$ & -- \\
\hline Data analysis and interpretation & $\checkmark$ & $\checkmark$ & $\checkmark$ & -- & -- & -- \\
\hline Writing the article & $\checkmark$ & -- & $\checkmark$ & -- & -- & -- \\
\hline Critical revision of the article & -- & $\checkmark$ & -- & $\checkmark$ & $\checkmark$ & $\checkmark$ \\
\hline Final approval of article & $\checkmark$ & $\checkmark$ & $\checkmark$ & $\checkmark$ & $\checkmark$ & $\checkmark$ \\
\hline Statistical analysis & -- & -- & -- & $\checkmark$ & -- & -- \\
\hline
\end{tabular}

\section{Acknowledgement and funding}

The authors are grateful to the Belgian Development Agency for its support in undertaking this study.

\section{Publication history}

Editor: Nicola Shaw, Algoma University, Canada. Received: 25-Apr-2017 Final Revised: 19-May-2017

Accepted: 23-May-2017 Published: 04-Jun-2017

\section{References}

1. Canavan A, Toonen J and Elovainio R. Performance Based Financing An international review of the literature. KIT Development Policy \& Practice. 2008. | Article

2. Yovoga RE and Djaton SK. Caractéristiques du pays et organisation de l'enquête. In Institut National de la Statistique et de l'Analyse Économique \& ICF International (Eds.), Quatrième Enquête Démographique et de Santé du Bénin 2011-2012. Calverton, Maryland USA: INSAE \& ICF International. 2013; 54. | Website

3. Raeburn J and Corbett T. Community development: How effective is it as an approach in health promotion? Paper prepared for the Second International Symposium on the Effectiveness of Health Promotion, University of Toronto. 2001.

4. Raeburn J and Rootman I. People-Centred Health Promotion. Chichester (England): John Wiley \& Sons. 1998. I Pdf

5. Community of Practice Health Service Delivery (COP). Renewing health districts for advancing universal health coverage in Africa. Report of the regional conference "Health districts in Africa: progress and perspectives 25 years after the Harare Declaration" 21-23 ${ }^{\text {rd }}$ October 2013, Dakar, Senegal. (Dakar Declaration). I Pdf

6. Toonen J and Coolen A. Le schéma du Financement Basé sur la Performance dans son contexte national: A la Recherche de Groupes de soutien au FBP en Afrique de l'Ouest. SNV/WA en collaboration avec I'Institut Royal des Tropiques (KIT). Accra, Février. 2010. | Article

7. World Health Organization. Alma Ata Déclaration on the Primary Health Care. Geneva, WHO. 1978. I Pdf

8. Morgan L. Results-Based Financing for Health: Signed, Sealed, Delivered? Evidence from Rwanda on the Impact of Results-based Financing for Health. The World Bank, 2009. I Website

9. McFarlane J and Fehir J. De Madres a Madres: a community, primary health care program based on empowerment. Health Educ Q. 1994; 21:381-94. | Article | PubMed

10. World health organization. Declaration on strengthening District health systems based on primary health care (Harare Declaration). International meeting on strengthening District health systems, Harare, Zimbabwe 3-7 August. 1987. I Pdf

11. Rusa L and Fritsche G. Rwanda: Performance-Based Financing in Health. In: Emerging Good Practice in Managing for Development Results: Sourcebook. Second Edition. 2007; 55-60. | Website

\section{Citation:}

Houeto D, Ghesquiere G, Agonnoude M, Hounouvi A, Gyselinck K and Drame ML. Benin experience of Decentralized Steering Committee in the institutional framework of Results-Based Financing: elements for players' empowerment at local level. J Public Health Aspects. 2017; 4:1.

http://dx.doi.org/10.7243/2055-7205-4-1 